\title{
Recombinant human relaxin versus placebo for cervical ripening: a double-blind randomised trial in pregnant women scheduled for induction of labour
}

\author{
Gerson Weiss ${ }^{*}$, Sam Teichman², Dennis Stewart ${ }^{2}$, David Nader², Susan Wood², Peter Breining ${ }^{2}$ \\ and Elaine Unemori ${ }^{2}$
}

\begin{abstract}
Background: Nonclinical studies indicate that the hormone relaxin is a good candidate for a safe cervical ripening agent that does not cause uterine contractions.

Methods: This Phase II study (conducted November 2, 2005-October 20, 2006) was a randomised, double blind, placebo controlled trial testing 24-h intravenous infusion of serelaxin (recombinant human relaxin) or placebo for cervical ripening in 72 healthy, primiparous women. Eligible subjects had a singleton pregnancy $\geq 40$ weeks, were planned for elective induction, had vertex presentation of the fetus, intact membranes and a Bishop score at screening $\leq 4$. In Part A of the study, safety evaluation of three escalating doses of serelaxin $(7.5,25 \mathrm{or} 75 \mu \mathrm{g} / \mathrm{kg} /$ day) or placebo was performed in 22 subjects admitted to the hospital $24 \mathrm{~h}$ prior to scheduled induction $(n=7,4$, 4 , and 7 subjects, respectively). The highest safe dose from Part A and placebo were then tested in Part B for safety and cervical ripening ( $n=25$ subjects/arm). Planned randomisation ratio was of 4:2 (serelaxin:placebo) for each dose group in Part A and 1:1 for Part B. For analysis, subjects in Part B were pooled with those receiving the same dose in Part $A$ and all subjects receiving placebo were pooled. The primary efficacy endpoint was change from baseline in Bishop score at 6, 12 and $24 \mathrm{~h}$ or end of study drug administration. Maternal safety evaluations included adverse events and vital signs through 4 weeks. Fetal assessments included serial heart rate monitoring and nonstress testing. Neonatal assessments included Apgar scores, NICU admissions, and adverse events through 4 weeks.
\end{abstract}

Results: Overall, 74 subjects were randomized and 72 were treated. There were no significant differences between the groups receiving the highest safe dose of serelaxin $(75 \mu \mathrm{g} / \mathrm{kg} /$ day $)$ and placebo in the primary or secondary efficacy endpoints. Changes from baseline in Bishop score at $24 \mathrm{~h}$ were $4.19 \pm 1.9$ and $3.26 \pm 2.26$ in the pooled placebo and serelaxin groups, respectively $(p=0.2507)$. Serelaxin was well tolerated and no anti-serelaxin antibodies were detected in either subjects or neonates.

Conclusion: Serelaxin infusion at the end of pregnancy was well tolerated but did not advance cervical ripening.

Trial registration: Clinicaltrials.gov identifier NCT00259103 (15 November 2005).

Keywords: Cervical ripening, Relaxin, Serelaxin

Abbreviations: AE, Adverse event; ECG, Electrocardiogram; IV, Intravenous; MTD, Maximum tolerated dose; NICU, Neonatal intensive care; PP, Per protocol; RXFP, Relaxin family peptide receptor; SAE, Serious adverse event; SBP, Systolic blood pressure; SD, Standard deviation; SEM, Standard error of the mean

\footnotetext{
* Correspondence: weissge@njms.rutgers.edu

${ }^{1}$ Department of Obstetrics, Gynecology and Women's Health, New Jersey

Medical School, Rutgers, The State University of New Jersey, Newark, NJ

07101, USA

Full list of author information is available at the end of the article
}

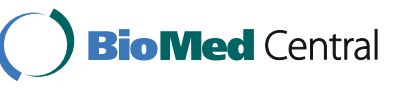

C 2016 The Author(s). Open Access This article is distributed under the terms of the Creative Commons Attribution 4.0 International License (http://creativecommons.org/licenses/by/4.0/), which permits unrestricted use, distribution, and reproduction in any medium, provided you give appropriate credit to the original author(s) and the source, provide a link to the Creative Commons license, and indicate if changes were made. The Creative Commons Public Domain Dedication waiver (http://creativecommons.org/publicdomain/zero/1.0/) applies to the data made available in this article, unless otherwise stated. 


\section{Background}

Induction of labour is one of the most common procedures in obstetrics, being performed in approximately $25 \%$ of women in industrialized countries [1]. In women with a high degree of cervical ripeness, induction of labour can usually be achieved with simple types of intervention [2]. Conversely, if the cervix is not ripe, induction of labour is much more likely to fail. In order to facilitate cervical softening, thinning and dilation for the purpose of enabling labour induction, both mechanical and pharmacologic ripening agents are utilized [2]. Prostaglandins are the most commonly used pharmacological aid and are effective in cervical preparation but are also associated with an increased risk of uterine hyperstimulation, potentially leading to fetal heart rate changes [2-4]. Estrogens, nitric oxide donors, and hyaluronidase have also been postulated as potential cervical ripening agents but currently, none are recommended for use in this regard $[2,4]$. Therefore, there is still a need for a cervical ripening agent that does not cause uterine contractions.

The naturally occurring hormone, relaxin, which mediates the hemodynamic changes that occur during pregnancy [5], causes cervical ripening in rodents and pigs [6]. In these species, serum relaxin is present from midpregnancy and increases markedly at the end of pregnancy in an "antepartum surge" that contributes to cervical ripening. Blocking relaxin activity using anti-relaxin neutralizing antibodies at this time inhibits cervical ripening in rats [7]. Relaxin- or relaxin receptor genedeficient mice demonstrate an impaired ability to deliver pups, largely due to defective cervical ripening $[8,9]$. In mice, relaxin causes a reduction in the density of collagen fibers [10], an alteration in aquaporin expression and an increase in hyaluronic acid content in the cervix [11]. These changes are associated with softening and increased distensibility of the cervix [12].

Although reports regarding the association between endogenous circulating relaxin levels and cervical ripening in women have generally shown a lack of correlation [13-17], relaxin binding sites are detected in the human cervix [18] and relaxin increases the expression of matrix metalloproteinases and glycosaminoglycans in cultured human cervical cells [19].

For these reasons, whether relaxin can cause cervical ripening has long been of clinical interest [20]. Multiple clinical trials have been conducted in the past to assess the ability of relaxin to enhance cervical ripening in a clinical setting [20-24]. Of these, a Cochrane review [25] included 4 blinded, randomized studies that tested intracervically and intravaginally administered purified porcine or recombinant human relaxin versus placebo and concluded that the data in these studies were not sufficient to recommend using relaxin to enhance labour or ripen the cervix. Pharmacokinetic analysis of intracervical and intravaginal application of serelaxin indicated that absorption via these topical routes is limited [26], suggesting that inadequate dosing may have played a role in the observed lack of efficacy. Therefore, whether relaxin can indeed ripen the cervix in women remained an open question.

We report the results of a completed clinical trial, which is listed in the Cochrane review as awaiting results [25] and tested intravenous (IV) administration of recombinant human relaxin (termed "serelaxin," the international nonproprietary name) versus placebo for the ability to ripen the cervix in late pregnant women. The specific trial objectives were: (1) to test the safety of 24-h IV serelaxin at pharmacological levels in pregnant women at $\geq 40$ weeks' gestation, and (2) to determine whether this mode of dosing could ripen the cervix and induce labour in these women.

\section{Methods}

This study was a prospective, randomized, double-blind, placebo-controlled pilot Phase II trial evaluating serelaxin for safety and efficacy in women $\geq 40$ weeks gestation admitted for elective induction of labour (clinicaltrials.gov identifier NCT00259103). It was conducted at 12 clinical sites, including teaching and community hospitals, in Russia between November 2, 2005 and October 20, 2006 in compliance with the protocol, International Conference on Harmonization, Good Clinical Practices, Ministry of Public Health and Social Development of the Russian Federation, local regulations and the standard operating procedures of the study sponsor, Corthera, Inc. (formerly BAS Medical). The protocol and informed consent were approved by the governing Ethics Committee at each study site and the Russian Federal Body for the Control of Pharmaceutical Agents. Subjects were screened for eligibility in approved clinics and hospitals by a small number of nurses or physicians specifically trained on the protocol and study logistics, including standardized assessment of the Bishop score [27]. Written informed consent was obtained from each patient before any study-related activity which was not part of routine care was undertaken, including the performance of diagnostic procedures to determine eligibility. The consent allows for publication of the study data.

Eligible patients were healthy primiparous women, $18-40$ years old with a singleton pregnancy, at $\geq 40$ weeks gestation, as defined by the date of the last menstrual period. Inclusion criteria included a Bishop score $\leq 4$, intact membranes, vertex presentation of the fetus, $<8$ uterine contractions per hour, a reactive fetal nonstress test, a pre-pregnancy BMI $\leq 29$ and a weight gain $\leq 18 \mathrm{~kg}$ 
during pregnancy. Exclusion criteria included hemoglobin $<8.5 \mathrm{gm} / \mathrm{dL}$, current diagnosis of hypertension, preeclampsia, weight $<50 \mathrm{~kg}$, planned and/or prior caesarean delivery or prior classical uterine incision, malpresentation of fetus, prolapsed umbilical cord, known fetal anomaly, or intrauterine growth restriction.

\section{Study design}

Eligible subjects were admitted $24 \mathrm{~h}$ prior to planned induction and assigned to receive serelaxin or matching diluent (placebo). Block randomisation was used for Part A with a ratio of 4:2 (serelaxin:placebo) per dose group and simple randomisation with a 1:1 ratio was used for Part B; no stratification variables were implemented. The randomisation scheme was generated by a contract research organization, Health Decisions Ltd. (Abingdon, UK), by personnel not involved in day-to-day conduct or monitoring of the study. Sites received randomisation numbers via secure web access centrally managed by Health Decisions. Upon subject randomisation, regional central pharmacies independent of the clinics and hospitals at which subjects were enrolled prepared study drug (provided by Corthera) and provided it in identical syringes labeled in blinded fashion to the study sites. Investigators, site personnel involved in treating and assessing patients, study operations personnel, including study monitors and medical monitors, and study subjects were blinded to treatment assignments.

The study was conducted in two parts:

Part A was a multi-center, randomized, double-blind, placebo-controlled, sequential dose escalation study evaluating the safety of 24-h continuous IV serelaxin at $7.5,25$, and $75 \mu \mathrm{g} / \mathrm{kg} /$ day, starting with the lowest dose. Study drug was infused using a syringe pump with infused volumes identical among all serelaxin doses and placebo to prevent unblinding. Doses were selected based on the safety profile and pharmacokinetic parameters observed in pregnant monkey studies [28-30], as well as in previously completed clinical trials in healthy volunteers or in other indications [26, 31]. Eighteen subjects were planned to be treated in cohorts of 6 and randomly assigned to receive serelaxin or placebo in a $4: 2$ ratio, respectively, in each cohort. Escalation to the next dose cohort occurred once maternal, fetal and neonatal safety data, including the one week postpartum assessments, were reviewed in blinded fashion by the study's medical monitors and found to be acceptable. Safety data evaluated included maternal, fetal and neonatal adverse events (AEs), vital signs, laboratory findings and physical examination. Dose escalation was not to occur if new, clinically significant findings indicating increased maternal, fetal or neonatal risk were observed. The highest safe dose of serelaxin (maximum tolerated dose [MTD]) was to be further studied for efficacy, as well as safety, in Part B.

Part B assessed the safety and efficacy of the MTD of serelaxin and was a multi-center, randomized, doubleblind, placebo-controlled, parallel-group study of 50 subjects randomized in a 1:1 ratio to serelaxin or to placebo. In both Parts A and B of the study, dosing was to be discontinued for onset of active labour, uterine hyperstimulation and abnormal fetal heart rate, or spontaneous rupture of membranes.

Because the rate of cervical ripening potentially induced by serelaxin was unknown, three time points within the $24 \mathrm{~h}$ treatment period were specified and the primary efficacy endpoint was change from baseline in Bishop score at 6, 12 and $24 \mathrm{~h}$ (or end of study drug administration). As a pilot study, this trial included multiple exploratory secondary efficacy endpoints, including proportion of subjects with Bishop score change $>3.0$, time to full dilation $(>10 \mathrm{~cm})$, time to delivery (vaginal or C-section), incidence of vaginal deliveries and spontaneous labour, and time to onset of active labour, were also collected in this study. The 24-h changes from baseline in individual components of the Bishop score were calculated post-hoc. The sample sizes in Part A were selected empirically. The sample size estimates for Part B were based on available data from previous trials of post-date pregnant women [24, 32, 33]. A mean baseline Bishop score of three and a mean change of three in the placebo group were estimated. Since there is no previous clinical experience with systemically administered serelaxin in cervical ripening, an estimated mean change in the active group of six, achievable by prostaglandins [32], was used. Thus a sample size of 25 per group in Part B has an $83 \%$ power to detect a difference of 3.0 in Bishop score between groups in Part B with an alpha of 0.05 . This sample size was also estimated empirically to allow observation of differences between serelaxin and placebo on a number of clinically relevant endpoints.

\section{Safety}

Maternal safety was assessed by monitoring for AEs, physical examination, ECG and vital signs at screening, baseline, serially during dosing and through $24 \mathrm{~h}$ postdosing and at 2 days, 1 week and 4 weeks post-partum. Clinical chemistry and hematology were assessed at baseline, 12 and $24 \mathrm{~h}$ following initiation of dosing, and 2 days, 1 week and 4 weeks postpartum. Fetal heart rate was monitored pre-dose and hourly from the start of dosing to $24 \mathrm{~h}$ and hourly from the start of active labour until delivery. Non-stress testing was performed predose and at 12 and $24 \mathrm{~h}$ during dosing. Neonatal safety was assessed by 1 and 5-min Apgar scores, admission to a neonatal intensive care unit (NICU) and vital signs at 
delivery, 2 days, 1 week and 4 weeks post-partum. Intensity of AEs was categorized by investigators using the following definitions:

- Mild: Usually transient requiring no special treatment; does not interfere with usual status or activities; awareness of event but easily tolerated

- Moderate: May be ameliorated by simple therapeutic measures; may cause enough discomfort to interfere with usual activities

- Severe: Causes inability to perform usual activities, requires close monitoring and/or intervention

- Very severe: Significantly debilitating or incapacitating despite symptomatic therapy, requires immediate intervention or emergency treatment, may be life-threatening

Serum serelaxin was measured in subjects prior to treatment and at 4, 12, and $24 \mathrm{~h}$ after initiation of dosing, $24 \mathrm{~h}$ after the end of dosing and in cord blood at delivery. Anti-serelaxin antibodies were measured in serum samples collected 1 and 4 weeks after delivery in subjects and in neonates.

\section{Statistical analysis}

For efficacy endpoint analysis, all subjects randomized to the placebo groups in Parts A and B were pooled ("pooled placebo") and all subjects receiving serelaxin in Part B were pooled with subjects in Part A receiving the same dose ("pooled MTD"). Because of the exploratory nature of the study, which was intended to aid in endpoint identification and sample size estimates for a subsequent larger study, this pooling was reasonable to slightly increase the power to detect differences. To explore the efficacy of a longer duration of dosing for advancement in Bishop score, a "Per Protocol" (PP) population receiving $\geq 18$ h of study drug was pre-specified. For analysis of safety, all randomized subjects receiving any amount of study drug were included.

Data analysis was conducted by SciAn Services (Toronto, Canada), a contracted data management organization. The database was locked prior to unblinding and no changes were made to the database after unblinding. Wilcoxon rank-sum test was used to assess the difference in change in Bishop score. Student's t-test or Chi-square test assessed differences in secondary end points. A $p$ value $<0.05$ was considered significant.

For hematology, chemistry, vital signs, physical examination and ECGs, summary statistics were provided for baseline and changes from baseline at each time point by treatment group.

Maternal AEs were recorded according to time of onset, i.e. dosing period $(0-24 \mathrm{~h}), 24$-h post-infusion (24$48 \mathrm{~h}$ ) and follow-up (>48 h). AEs reported in fetuses and in neonates were summarized by treatment group. AEs were coded using the standardized MedDRA dictionary.

\section{Relaxin and anti-relaxin antibody assays}

Serum serelaxin was measured in an ELISA validated for measurement of serelaxin in human serum (sensitivity $96 \mathrm{pg} / \mathrm{mL}$ ) and according to Good Laboratory Practices (GLP). Because serelaxin is identical to endogenous relaxin-2, both are recognized by the assay and results are presented for "serelaxin and relaxin".

A GLP screening assay validated for measurement of serum antibodies to human serelaxin was used. If positive, samples were to be titered and checked for specificity by inhibition of binding with serelaxin.

\section{Results}

A total of 74 subjects were randomized (Fig. 1). Two subjects went into spontaneous labour post-randomisation before treatment initiation and are excluded from all analyses. Seventy-two subjects were treated as randomized ("All Treated" population), 40 with serelaxin and 32 with placebo. Demographics were similar among subjects randomized to the two groups. Overall, the average age of the study population was 24 years with means of a BMI of $26 \mathrm{~kg} / \mathrm{m}^{2}$, a pre-pregnancy weight of $60 \mathrm{~kg}$, were at 40.6 weeks' gestation, $85 \%$ were Caucasian and $15 \%$ were Asian. The average Bishop score was $2.1 \pm 1.5$ (mean \pm $\mathrm{SD})$ at both screening and at the pre-dose assessment.

Study drug was stopped prior to $24 \mathrm{~h}$ due to labour onset in $4(13 \%)$ and eight subjects $(20 \%)$ in the placebo and serelaxin groups, respectively. Drug was also discontinued due to rupture of membranes in one subject in each of the placebo (6\%) and serelaxin (5\%) groups. Fifty-six of the 72 subjects $(78 \%)$ received $\geq 18 \mathrm{~h}$ of study drug infusion (PP population).

Part A: Six subjects were randomized to the first cohort of Part A and an additional 4 were enrolled during the safety assessment period (Fig. 1). Therefore, in the first cohort, seven subjects received $7.5 \mu \mathrm{g} / \mathrm{kg} /$ day serelaxin and three subjects received placebo. The maternal, fetal and neonatal safety data, including AEs, vital signs, laboratory findings and physical examination, were found to be acceptable, so six subjects were randomized to the second cohort, receiving $25 \mu \mathrm{g} / \mathrm{kg} /$ day relaxin $(n=4)$ or placebo $(n=$ $2)$. Once safety in these subjects was affirmed, six subjects were dosed with $75 \mu \mathrm{g} / \mathrm{kg} /$ day serelaxin $(n=$ $4)$ or placebo $(n=2)$ in the third cohort. Based on the acceptable safety data from the 22 subjects in Part A, including similar types and distribution of AEs between groups and few AEs occurring in more than one individual, the $75 \mu \mathrm{g} / \mathrm{kg} /$ day serelaxin dose was determined to be the MTD and selected for study in Part B. 


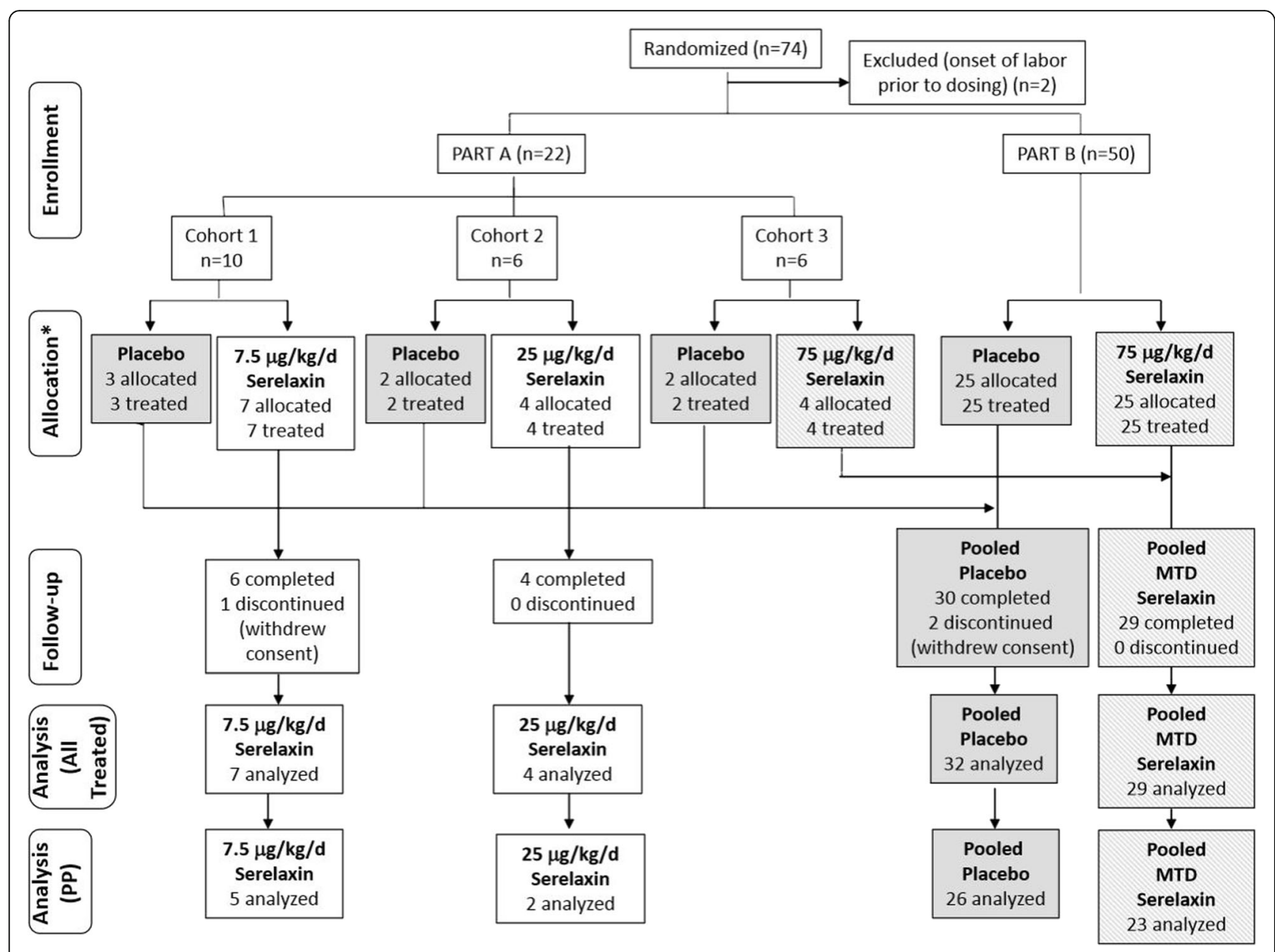

Fig. 1 Trial profile (CONSORT 2010). PP Per protocol (received $\geq 18 \mathrm{~h}$ of study drug infusion). *All subjects were treated as allocated

Part B: Fifty patients were enrolled in Part B. Serelaxin-treated subjects in Part B $(n=25)$ were pooled with subjects in Part A who received the same serelaxin dose of $75 \mu \mathrm{g} / \mathrm{k} /$ day $(n=4)$ for a total of 29 subjects in the pooled MTD group, and all subjects receiving placebo in Parts A $(n=7)$ and B $(n=25)$ were pooled for a total of 32 subjects in the pooled placebo group (Fig. 1). The mean treatment duration (mean \pm SD) was similar in the serelaxin $(22.3 \pm 4.2 \mathrm{~h})$ and placebo groups $(21.4 \pm$ $6.1 \mathrm{~h})$. Baseline characteristics of subjects enrolled in the pooled MTD and placebo groups were similar. The average ages were 24 and 25 years, with a BMI of 26 and $27 \mathrm{~kg} / \mathrm{m} 2$, respectively, and both groups were at an average of 40.6 weeks' gestation. Ninety and $91 \%$ were Caucasian in the pooled MTD and placebo groups, respectively, and $3 \%$ were Asian in both groups.

The average Bishop score (mean \pm SD) at baseline in the All Treated population was $2.2 \pm 1.3$ vs. $1.9 \pm 1.6$ in the pooled MTD and pooled placebo groups, respectively $(p=$ NS) (Table 2$)$. There were no statistically significant differences between groups in changes from baseline in Bishop score at any time point or when measured immediately prior to cessation of dosing (Table 1). Changes from baseline in Bishop score at $24 \mathrm{~h}$ in the All Treated population were $4.19 \pm 1.9$ and $3.26 \pm 2.26$ in the pooled placebo and serelaxin groups, respectively $(p=$ 0.2507). In the PP population, the mean baseline Bishop score measured $2.1 \pm 1.3$ in the pooled placebo group and $1.6 \pm 1.6$ in the pooled MTD group $(p=N S)$. At the $12 \mathrm{~h}$ time point, the increase from baseline in Bishop score was larger in the pooled placebo than in the pooled MTD group $(p=0.0418)$. No other differences between the two groups were observed. A post-hoc analysis of the changes from baseline in the individual components of the Bishop score revealed no significant differences between the pooled placebo and MTD groups in any of the components (Table 2). None of the secondary efficacy endpoints showed differences between the pooled placebo and pooled MTD groups (Table 3).

The treatment groups showed similar chemistry and hematology characteristics. Serum creatinine and BUN 
Table 1 Mean changes from baseline in bishop score in the all treated and per protocol (PP) populations

\begin{tabular}{|c|c|c|c|c|c|c|}
\hline & \multicolumn{6}{|l|}{ Mean \pm SD } \\
\hline & \multicolumn{6}{|c|}{ Active $(\mu \mathrm{g} / \mathrm{kg} /$ day $)$} \\
\hline & \multicolumn{3}{|l|}{ Part A } & \multirow{2}{*}{$\begin{array}{l}\text { Part B } \\
75\end{array}$} & \multirow{2}{*}{$\begin{array}{l}\text { Pooled MTDa } \\
75\end{array}$} & \multirow{2}{*}{$\begin{array}{l}\text { Pooled Placebo } \\
\text { Placebo }\end{array}$} \\
\hline & 7.5 & 25 & 75 & & & \\
\hline \multicolumn{7}{|l|}{ All Treated population } \\
\hline $\mathrm{N}$ & 7 & 4 & 4 & 25 & 29 & 32 \\
\hline Baseline & $2.6 \pm 1.6$ & $2.5 \pm 1.9$ & $2.5 \pm 1.9$ & $2.2 \pm 1.2$ & $2.2 \pm 1.3$ & $1.9 \pm 1.6$ \\
\hline \multicolumn{7}{|l|}{ Change from Baseline: } \\
\hline $6 \mathrm{~h}$ & $1.29 \pm 0.95$ & $1.25 \pm 0.96$ & $1.50 \pm 1.91$ & $1.56 \pm 2.20$ & $1.55 \pm 2.13$ & $1.77 \pm 1.45$ \\
\hline $12 \mathrm{~h}$ & $2.43 \pm 1.13$ & $2.25 \pm 1.71$ & $2.00 \pm 1.63$ & $2.13 \pm 2.11$ & $2.11 \pm 2.02$ & $2.64 \pm 1.64$ \\
\hline $24 \mathrm{~h}$ & $3.20 \pm 0.84$ & $3.00 \pm 4.24$ & $2.50 \pm 1.91$ & $3.42 \pm 2.34$ & $3.26 \pm 2.26$ & $4.19 \pm 1.90$ \\
\hline Last observation ${ }^{\mathrm{b}}$ & $3.43 \pm 0.79$ & $2.75 \pm 2.50$ & $2.50 \pm 1.91$ & $3.76 \pm 2.57$ & $3.59 \pm 2.50$ & $4.03 \pm 1.90$ \\
\hline \multicolumn{7}{|l|}{ PP population } \\
\hline $\mathrm{N}$ & 5 & 2 & 4 & 19 & 23 & 26 \\
\hline Baseline & $3.0 \pm 1.7$ & $2.0 \pm 2.8$ & $2.5 \pm 1.9$ & $2.0 \pm 1.2$ & $2.1 \pm 1.3$ & $1.6 \pm 1.6$ \\
\hline \multicolumn{7}{|l|}{ Change from Baseline: } \\
\hline $6 \mathrm{~h}$ & $1.00 \pm 0.71$ & $1.00 \pm 1.41$ & $1.50 \pm 1.91$ & $0.84 \pm 1.21$ & $0.96 \pm 1.33$ & $1.65 \pm 1.38$ \\
\hline $12 \mathrm{~h}^{\mathrm{c}}$ & $1.80 \pm 0.45$ & $2.00 \pm 2.83$ & $2.00 \pm 1.63$ & $1.63 \pm 1.67$ & $1.70 \pm 1.64$ & $2.62 \pm 1.60$ \\
\hline $24 \mathrm{~h}$ & $3.20 \pm 0.84$ & $3.00 \pm 4.24$ & $2.50 \pm 1.91$ & $3.42 \pm 2.34$ & $3.26 \pm 2.26$ & $4.19 \pm 1.90$ \\
\hline Last observation ${ }^{\mathrm{b}}$ & $3.20 \pm 0.84$ & $3.00 \pm 4.24$ & $2.50 \pm 1.91$ & $3.42 \pm 2.34$ & $3.26 \pm 2.26$ & $4.19 \pm 1.90$ \\
\hline
\end{tabular}

The Bishop score ranges from 0 (absence of any cervical changes) to a maximum of 13 , representing a cervix that is dilated ( $>5 \mathrm{~cm}$ ), effaced ( $>80 \%)$, soft, at a +1 or +2 station, and anteriorly positioned. ${ }^{26}$ If the total Bishop score was calculated $>13$, then ' $13^{\prime}$ was used. Change was calculated as Bishop score at time point Bishop score at baseline. All Treated population includes all patients treated with any amount of study drug. Per protocol (PP) population includes all patients treated for at least $18 \mathrm{~h}$ of study drug

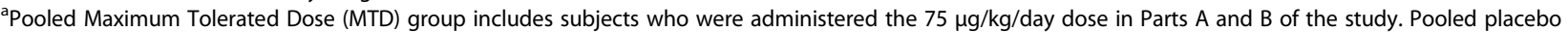
group includes all subjects who received placebo in Parts $A$ and $B$

${ }^{b}$ Last observation was defined as the last available value observed during dosing

'Difference between the pooled MTD and pooled placebo groups at $12 \mathrm{~h}, p=0.042$ by Wilcoxon Rank Sum test. No other differences were significant

trended lower in the MTD group than in the placebo group at the 12 and $24 \mathrm{~h}$ time points; none of the differences were statistically significant except for lower BUN in the MTD group at the $24 \mathrm{~h}$ measurement $(p=0.02)$. Mean decreases from baseline in systolic blood pressure (SBP) during dosing were consistently slightly greater but not statistically different in the MTD group

Table 2 Mean changes from baseline in components of the bishop score at $24 \mathrm{~h}$

\begin{tabular}{lcc}
\hline & \multicolumn{2}{c}{ Mean \pm SD } \\
\cline { 2 - 3 } & $\begin{array}{l}\text { Pooled MTD } \\
n=26\end{array}$ & $\begin{array}{l}\text { Pooled Placebo } \\
n=23\end{array}$ \\
\hline Cervical Dilatation (cm) & $0.63 \pm 0.81$ & $1.35 \pm 1.21$ \\
Effacement (\%) & $0.43 \pm 0.59$ & $0.65 \pm 0.75$ \\
Station & $0.50 \pm 1.45$ & $0.44 \pm 0.71$ \\
Consistency & $0.83 \pm 0.78$ & $0.92 \pm 0.63$ \\
Position of Cervix & $0.83 \pm 0.83$ & $1.19 \pm 0.69$ \\
\hline
\end{tabular}

Mean changes from baseline in the individual components of the Bishop score at $24 \mathrm{~h}$ were calculated post-hoc in all patients receiving $24 \mathrm{~h}$ of study drug with Bishop scores available at baseline and $24 \mathrm{~h}$

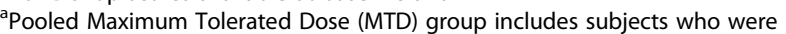
administered the $75 \mu \mathrm{g} / \mathrm{kg} /$ day dose in Parts A and B of the study. Pooled placebo group includes subjects who received placebo in Parts $A$ and $B$ compared to the placebo group at all time points after $10 \mathrm{~min}$. No consistent changes in heart rate were noted in study subjects or fetuses, either during or post-dosing.

Serum serelaxin + relaxin concentration (mean \pm SEM) in the pooled MTD group was $8.27 \pm 1.10 \mathrm{ng} / \mathrm{mL}$ at the 4-h and $13.03 \pm 1.49 \mathrm{ng} / \mathrm{mL}$ at the 12 -h time point (Fig. 2). Levels in the placebo group reflecting endogenous relaxin at these time points were $0.44 \pm 0.19$ and $0.27 \pm 0.03 \mathrm{ng} / \mathrm{mL}$, respectively. Levels were below the detection limit of the assay in the majority of cord blood. No anti-relaxin antibodies were detectable in any of the subjects or neonates either at 1 week or 4 weeks postpartum.

\section{Safety}

Safety was assessed in all subjects receiving any amount of study drug ( $n=32$ in the pooled placebo group and $n=40$ in the pooled serelaxin group). Serelaxin was well tolerated in subjects, fetuses and neonates; AEs were generally balanced between treatment groups. Sixteen subjects, 8 $(20.0 \%)$ and $8(25.0 \%)$ in the serelaxin (all doses) and placebo groups, respectively, had 19 AEs during the 24-h dosing period. The most common maternal AE during 
Table 3 Secondary efficacy endpoints in the all treated population

\begin{tabular}{|c|c|c|c|}
\hline & $\begin{array}{l}\text { Pooled MTD } \\
(n=29)\end{array}$ & $\begin{array}{l}\text { Pooled Placebo }{ }^{a} \\
(n=32)\end{array}$ & $p$ value \\
\hline Proportion of Subjects with $24 \mathrm{~h}$ Change from Baseline in Bishop Score $>3^{\mathrm{b}}$ & $13 / 23(56.5 \%)$ & $18 / 26(69.2 \%)$ & 0.36 \\
\hline Incidence of Spontaneous Labour ${ }^{d}$ & $12 / 29(41.4 \%)$ & $20 / 32(62.5 \%)$ & 0.12 \\
\hline Incidence of Vaginal Deliveries ${ }^{d}$ & $20 / 29(69.0 \%)$ & $27 / 32(84.4 \%)$ & 0.15 \\
\hline Time to Vaginal Delivery, Mean $\pm S D^{c}$ & $62.3 \pm 40.2 \mathrm{~h}$ & $54.3 \pm 29.3 \mathrm{~h}$ & 0.64 \\
\hline Time to Delivery (Vaginal $+C$-section), Mean $\pm S^{c}$ & $66.8 \pm 39.6 \mathrm{~h}$ & $54.5 \pm 30.1 \mathrm{~h}$ & 0.25 \\
\hline Time to Complete Dilation $(10 \mathrm{~cm})$, Mean $\pm \mathrm{SD}^{c}$ & $57.5 \pm 39.5 \mathrm{~h}$ & $52.7 \pm 26.2 \mathrm{~h}$ & 1.00 \\
\hline Time to Onset of Active Labour ${ }^{\mathrm{e}}$, Mean $\pm S D^{c}$ & $53.2 \pm 36.3 \mathrm{~h}$ & $45.8 \pm 29.9 \mathrm{~h}$ & 0.41 \\
\hline
\end{tabular}

aPooled Maximum Tolerated Dose (MTD) group includes subjects who were administered the $75 \mu \mathrm{g} / \mathrm{kg} /$ day dose in Parts A and B of the study. Pooled placebo group includes all subjects who received placebo in Parts A and B

${ }^{\mathrm{b}}$ Subjects included have Bishop scores available at both baseline and $24 \mathrm{~h}$

$c_{p}$ value was calculated using the Wilcoxon Rank-sum test

${ }^{d} p$ value was calculated using the Chi-square test

${ }^{\mathrm{e}}$ Active labour was defined as having $35-45 \mathrm{~s}$ contractions every 3 min with $4 \mathrm{~cm}$ dilation

dosing was tachycardia of mild severity (Table 4). AEs occurred in slightly more subjects in the pooled placebo (12 [38 \%]) than pooled serelaxin (9 [23\%]) group during the $24 \mathrm{~h}$ post-infusion period, as well as during the follow up period (17 [53 \%] and 19 [48\%] in the placebo and serelaxin groups, respectively).

There were no maternal, fetal or neonatal deaths in the study. One maternal serious AE (SAE) was reported, cephalopelvic disproportion of moderate severity in a subject receiving placebo, occurring during labour and delivery. A C-section was performed and the subject recovered.

AEs occurred in 16 fetuses, 9 (22.5\%) in the serelaxin and $7(21.9 \%)$ in placebo groups and were balanced between groups (Table 5). SAEs (all considered unrelated to study drug) were reported in three fetuses: acute fetal

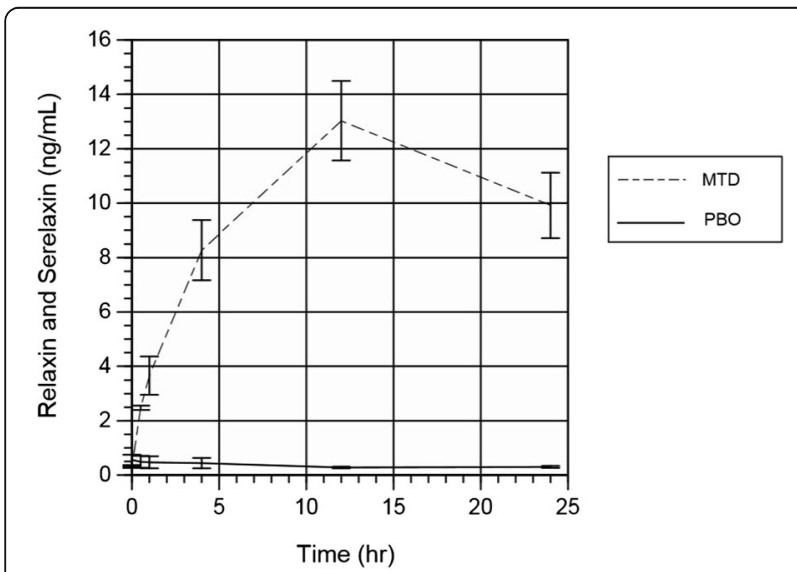

Fig. 2 Plasma concentrations of relaxin and serelaxin. Plasma levels of relaxin + serelaxin (mean \pm SEM), measured at baseline $(0)$ and at 6,12 , and $24 \mathrm{~h}$ from the start of study drug administration in primiparous women $\geq 40$ weeks of pregnancy in the pooled placebo and pooled MTD serelaxin groups. In the placebo group, only endogenous relaxin- 2 is measured, while in the pooled MTD group, both serelaxin and endogenous relaxin-2 are detected distress of moderate severity in the placebo group and two SAEs of fetal hypoxia of moderate severity in the serelaxin group, neither of which required action or medication; all fetuses recovered. All fetuses had reactive results at 12 and $24 \mathrm{~h}$, with the majority having reactive results within the first $20 \mathrm{~min}$ and all within $40 \mathrm{~min}$.

AEs were reported in 39 neonates, 19 (47.5\%) in the serelaxin and $20(62.5 \%)$ in the placebo groups. The most common AE was cerebral ischemia (8/32 [25 \%] in

Table 4 Maternal adverse events

\begin{tabular}{lll}
\hline $\begin{array}{l}\text { Observation Period } \\
\text { Adverse Event Preferred Term }\end{array}$ & \multicolumn{2}{l}{ Number (\%) of Subjects } \\
\cline { 2 - 3 } & $\begin{array}{l}\text { Pooled Placebo } \\
(n=32)^{\mathrm{a}}\end{array}$ & $\begin{array}{l}\text { Pooled Serelaxin } \\
(n=40)^{\mathrm{a}}\end{array}$ \\
\hline $\begin{array}{l}\text { Study Drug Dosing } \\
\text { Tachycardia }\end{array}$ & $2(5.0)$ \\
$\begin{array}{l}\text { 24-h Post-infusion } \\
\text { Amniotic fluid decreased }\end{array}$ & $3(9.4)$ & $0(0.0)$ \\
$\begin{array}{l}\text { Labour complication } \\
\text { Post-partum vaginal }\end{array}$ & $3(9.4)$ & $0(0.0)$ \\
laceration & $3(9.4)$ & $2(5.0)$ \\
$\begin{array}{l}\text { Uterine cervical laceration } \\
\text { during labour }\end{array}$ & $4(12.5)$ & $2(5.0)$ \\
$\begin{array}{l}\text { Uterine hypotonus } \\
\text { 48-h Post-infusion (follow-up) }\end{array}$ & $2(6.3)$ & $3(7.5)$ \\
$\begin{array}{l}\text { Amniotic fluid decreased } \\
\text { Uterine cervical laceration } \\
\text { during labour }\end{array}$ & $4(12.5)$ & $3(18.8)$ \\
$\begin{array}{l}\text { Uterine hypotonus } \\
\text { Uterine hemorrhage }\end{array}$ & $2(6.3)$ & $4(10.0)$ \\
\hline
\end{tabular}

Listed are all adverse events occurring in $>5 \%$ in either arm during study drug dosing, within the 24-h post-infusion period and within the follow up period

The pooled placebo group includes all subjects from Parts $A$ and $B$ treated with placebo and the pooled serelaxin group includes all subjects from Parts $A$ and $B$ treated with any dose of serelaxin 
Table 5 Fetal and neonatal adverse events in the all treated population

\begin{tabular}{|c|c|c|}
\hline Adverse Event Preferred Term & $\begin{array}{l}\text { Pooled Placebo } \\
(n=32)^{\mathrm{a}}\end{array}$ & $\begin{array}{l}\text { Pooled Serelaxin } \\
(n=40)^{\mathrm{a}}\end{array}$ \\
\hline & \multicolumn{2}{|c|}{ Number (\%) of Fetuses } \\
\hline Tachycardia & $2(6.3)$ & $1(2.5)$ \\
\hline \multirow[t]{2}{*}{ Hypoxia } & $3(9.4)$ & $3(7.5)$ \\
\hline & \multicolumn{2}{|c|}{ Number (\%) of Neonates } \\
\hline Conjunctivitis & $4(12.5)$ & $1(2.5)$ \\
\hline Regurgitation of food & $1(3.1)$ & $3(7.5)$ \\
\hline Cerebral ischemia & $8(25.0)$ & $3(7.5)$ \\
\hline Torticollis & $4(12.5)$ & $2(5.0)$ \\
\hline Hypertonia & $3(8.4)$ & $0(0.0)$ \\
\hline Hypoglycemia & $3(9.4)$ & $2(5.0)$ \\
\hline Jaundice & $2(6.3)$ & $5(12.5)$ \\
\hline Neonatal hypoxia & $7(21.9)$ & $7(17.5)$ \\
\hline Neonatal agitation & $7(21.9)$ & $4(10.0)$ \\
\hline Hypotonia & $6(18.8)$ & $6(15.0)$ \\
\hline Neonatal asphyxia & $6(18.8)$ & $4(10.0)$ \\
\hline Poor weight gain & $1(3.1)$ & $3(7.5)$ \\
\hline Postmature baby & $7(21.9)$ & $1(2.5)$ \\
\hline Umbilical cord around neck & $5(15.6)$ & $3(7.5)$ \\
\hline Dermatitis diaper & $3(9.4)$ & $1(2.5)$ \\
\hline
\end{tabular}

Listed are fetal and neonatal AEs occurring in $>5 \%$ in either arm

${ }^{\text {a T}}$ The pooled placebo group includes all fetuses or neonates from Parts A and $B$ treated with placebo and the pooled serelaxin group includes all subjects from Parts A and B treated with any dose of serelaxin

the placebo group and 3/40 [7.5 \%] in the serelaxin group) (Table 5). Eleven SAEs (all determined to be unrelated to study drug) were reported in three neonates $(9.4 \%)$ in the placebo and $5(12.5 \%)$ in the serelaxin group. All neonates recovered from the SAEs, except for macrostomia, which was ongoing at the end of the study. Average Apgar scores were in the normal range, $\geq 7$, for all neonates. Four NICU admissions occurred in each treatment group. At 1 week, two neonates in the placebo group remained in the NICU and at 4 weeks, one remained.

\section{Discussion}

This study was the first to test the ability of serelaxin systemically administered at the end of pregnancy to ripen the cervix. Unlike the topical modes of administration used in previous clinical trials [20-24], IV serelaxin ensured adequate exposure of the cervix at a pharmacological dose and provided an antepartum surge of serelaxin of 20-30-fold higher than endogenous relaxin. The results indicated that while serelaxin was well tolerated, it did not enhance cervical ripening or affect relevant clinical parameters, including time to active labour, frequency of spontaneous labour or time to delivery.
Because the results of this study were negative and serelaxin was being developed by the study sponsor for another therapeutic indication [34-36], publication of these data was not a priority and considerable time has elapsed since the study concluded. There was no embargo on publication and the results were presented at a meeting $\left(5^{\text {th }}\right.$ International Conference on Relaxin and Relaxin-Related Peptides, 2008) in timely manner and published in brief in meeting proceedings [37]. However, because there is continued interest in the potential ability of serelaxin to cause cervical ripening [4], the authors considered these data to be relevant and worthy of publication.

The negative results in this study may be related to the natural history of relaxin, which is speciesspecific in patterns of expression during pregnancy. In rodents and pigs, relaxin levels increase at the end of pregnancy in an antepartum surge of 5-20fold mid-pregnancy levels [6] and a relaxin deficiency inhibits the dispersion of cervical collagen fibers that normally occurs during this time [7-9]. In women, relaxin levels peak during the first trimester and remain elevated compared to non-pregnancy levels throughout gestation but an antepartum surge is not observed [38], perhaps indicating a difference in relaxin biology relative to cervical ripening among these species.

Studies in rodents have indicated that relaxin also has hemodynamic properties starting mid-pregnancy when levels rise in these species [5]. Serelaxin clinical trials in other indications or in healthy volunteers have demonstrated changes in systemic and renal hemodynamics [34, 39-41], indicating that these effects translate to the human. There were trends in the current trial suggesting serelaxin slightly decreased SBP, consistent with this aspect of serelaxin pharmacology. Perhaps relaxin's major physiological role in human pregnancy relates to maternal hemodynamic adjustments, rather than cervical ripening.

However, it is also possible that an extended duration of exposure and/or a higher serelaxin dose might enhance cervical ripening. A 24-h infusion in the setting of a clinical trial was estimated to be the longest duration consistent with management of postdate pregnant women and the dose tested did achieve a pharmacologic level that was 20-30-fold higher than physiologic exposures. Therefore, it is felt that the trial design afforded a reasonable method to test the hypothesis of therapeutic serelaxin-mediated cervical ripening.

Earlier clinical studies reported positive results of topically applied porcine relaxin [20-22], suggesting that pig relaxin may be more efficacious than human relaxin in this regard. Receptor (RXFP1) binding studies using 
pig relaxin have not supported this hypothesis [41], and although pig relaxin does bind with higher affinity than human relaxin to the low affinity serelaxin receptor (RXFP2), to date this receptor has not been shown to be expressed in the cervix [42]. That the RXFP2 is the receptor primarily responsible for cervical ripening in the human cannot be excluded as a possibility, but serum serelaxin at the concentrations achieved in this study should have engaged and activated both RXFP1 and -2 .

In summary, this study was well designed and appropriate to test the hypothesis in that it was randomized, double blind and placebo controlled. It was designed to be a safety and exploratory dose-finding study, and a safe pharmacological serelaxin dose, whose delivery and exposure was confirmed by pharmacokinetic testing, was identified. Limitations included enrollment of small numbers of subjects from a relatively large number of institutions and the inability to test longer infusions of serelaxin. Multiple efficacy endpoints were evaluated to provide preliminary evidence of efficacy and to determine appropriate endpoints for further testing in a larger phase III study. No adjustments for multiplicity were made within any of the analyses performed; however, this would not have affected the negative results.

\section{Conclusions}

This study indicates that a 24-h exposure to an IV infusion of $75 \mu \mathrm{g} / \mathrm{kg} /$ day serelaxin at the end of pregnancy was well tolerated by the subjects, fetuses, and neonates, consistent with the safety profile demonstrated in other clinical trials under conditions of much greater systemic exposure [43]. Serelaxin did not advance cervical ripening or labour.

\section{Acknowledgements}

The authors would like to thank Dr. Laura Goldsmith for helpful suggestions on the manuscript.

\section{Funding}

This study was funded by the sponsor, Corthera, Inc. (formerly BAS Medical). The author who was not employed by the study sponsor (G.W.) was the academic Principal Investigator, had full authority over the scientific methodology, including study design, had full access to all data and analyses, ultimate editorial authority and final responsibility for the decision to submit the manuscript for publication. Data collection and analysis were performed by the research organizations, Health Decisions and SciAn Services, respectively, which were contracted by sponsor. Study results were interpreted by the authors of the manuscript in collaboration with SciAn. Novartis Pharmaceuticals Company (East Hanover, New Jersey) currently owns the data and has reviewed the manuscript.

\section{Availability of data and materials}

The clinical data are not publicly available.

\section{Authors' contributions}

ST and GW were the study's medical monitors and participated in designing the study protocol, implementing the study, interpreting the data and drafting the manuscript. DS managed conduct of and interpretation of the data from the serelaxin and anti-serelaxin assays. DN and SW contributed substantially in implementing the study and in data acquisition and review. PB contributed substantially in implementing the study. EU participated in designing the study protocol, implementing the study, interpreting the data and drafting the manuscript. All authors have reviewed and approved of the final manuscript.

\section{Authors' information \\ 1 Department of Obstetrics, Gynecology and Women's Health, New Jersey Medical School, Rutgers, The State University of New Jersey, Newark, New Jersey 07101, USA \\ ${ }^{2}$ At the time of study conduct, an employee of Corthera, Inc. (formerly BAS Medical), 1660 South Amphlett Blvd., San Mateo, CA 94402, USA; Corthera was acquired by Novartis Pharmaceutical Company in February 2010.}

\section{Competing interests}

GW received financial compensation as medical consultant to the sponsor during planning and conduct of the study. ST, DS, DN, SW, PB and EU were employed by the sponsor at the time of study conduct.

\section{Ethics approval and consent to participate}

Written informed consent was received from every subject in this study. The consent allows for publication of the study results. Ethics approval for the study protocol and informed consent was received at each of the 12 hospitals in Russia at which the study was conducted (State Educational Institution of High Professional Education, Kasan State Medical University of Federal Agency of Healthcare and Social Development, Obstetrics and Gynecology Department, Kasan; State Institution D.O. Ott Research Institute of Obstetrics and Gynecology of Russian Academy of Medical Sciences, Saint Petersburg; Novosibirsk State Medical Academy, Novosibirsk; Moscow Regional Research Institute of Obstetrics and Gynecology, Moscow; Maternity Hospital No. 15, Saint Petersburg; Ural Research Institute of Maternity and Newborn Protection, Department of Antenatal Newborn Protection, Ekatinerinburg; State Educational Institute of Higher Professional Education, Kemerovo State Medical Academy of Federal Agency of Healthcare and Social Development, Obstetrics and Gynecology Department No. 2 on the base of State Institution of Healthcare Maternity Hospital of Regional Clinical Hospital, Kemerovo; State Educational Institute of Higher Professional Education, Kemerovo State Medical Academy of Federal Agency of Healthcare and Social Development, Obstetrics and Gynecology Department No. 1 on the base of Municipal Institution of Healthcare Kemerovo City Clinical Hospital No. 3 named after M.A. Podgorbunskiy, Kemerovo; State Medical University of Russia, Pediatric Faculty, Department of Obstetrics and Gynecology on the base of State Institution of Healthcare of Moscow, Moscow Family Planning Center, Moscow; State Institution of Healthcare 2nd Regional Hospital, Rostov-on-Don; Saint Petersburg State University, Medical Faculty, Department of Obstetrics and Gynecology on the base of Saint Petersburg State Institution of Healthcare Maternity Hospital No. 11, Saint Petersburg; State Educational Institution of Higher Professional Education, Siberian State Medical University of Federal Agency of Healthcare and Social Development, Obstetrics and Gynecology Department, Tomsk).

\section{Author details}

${ }^{1}$ Department of Obstetrics, Gynecology and Women's Health, New Jersey Medical School, Rutgers, The State University of New Jersey, Newark, NJ 07101, USA. ${ }^{2}$ At the time of study conduct, an employee of Corthera, Inc. (formerly BAS Medical), 1660 South Amphlett Blvd., San Mateo, CA 94402, USA.

Received: 16 January 2016 Accepted: 8 July 2016

Published online: 05 September 2016

\section{References}

1. WHO recommendations for induction of labour 2011; Geneva: World Health Organisation; 2011.

2. Royal College of Obstetrics and Gynaecologists, RCOG Clinical Effectiveness Support Unit. Induction of labour. Evidence-based Clinical Guideline Number 9. London: RCOG Press; 2008

3. Kelly AJ, Kavanagh J, Thomas J. Vaginal prostaglandin (PGE2 and PGF2a) for induction of labour at term. Cochrane Database Syst Rev. 2009;7:CD003101.

4. Mozurkewich EL, Chilimigras JL, Berman DR, Perni UC, Romero VC, King VJ, Keeton KL. Methods of induction of labour: a systematic review. BMC Pregnancy Childbirth. 2011;11:84. 
5. Conrad KC. Maternal vasodilation in pregnancy: the emerging role of relaxin. Am J Physiol Regul Integr Comp Physiol. 2011;301:R267-275.

6. Bathgate RAD, Hsueh AJW, Sherwood OD. Physiology and molecular biology of the relaxin peptide family. In: Neill JD, Plant TM, Pfaff DW, Challis JRG, de Kretser DM, Richards JS, Wassarman PM, editors. Knobil and Neill's physiology of reproduction, $3^{\text {rd }}$ ed. New York: Elsevier Press; 2006. p. 679-768.

7. Hwang JJ, Shanks RD, Sherwood OD. Monoclonal antibodies specific for rat relaxin. IV. Passive immunization with monoclonal antibodies during the antepartum period reduces cervical growth and extensibility, disrupts birth, and reduces pup survival in intact rats. Endocrinology. 1989;125:260-6.

8. Zhao L, Samuel CS, Tregear GW, Beck F, Wintour EM. Collagen studies in late pregnant relaxin null mice. Biol Reprod. 2000;63:697-703.

9. Krajnc-Franken MAM, van Disseldorp AJM, Koenders JE, Mosselman S, van Duin M, Gossen JA. Impaired nipple development and parturition in LGR7 knockout mice. Mol Cell Biol. 2004;24:687-96.

10. Luque EH, de Toro MM M, Ramos JG, Rodriguez HA, Sherwood OD. Role of relaxin and estrogen in the control of eosinophilic invasion and collagen remodeling in rat cervical tissue at term. Biol Reprod. 1998;59:795-800.

11. Soh YM, Tiwari A, Mahendroo M, Conrad KP, Parry LJ. Relaxin regulates hyaluron synthesis and aquaporins in the cervix of late pregnant mice. Endocrinology. 2012;153:6054-64

12. Shi L, Shi S-Q, Saade GR, Chwalisz K, Garfield RE. Studies of cervical ripening in pregnant rats: effects of various treatments. Mol Hum Reprod. 2000;6:382-9.

13. Eppel W, Kucera E, Biegelmayer C. Relationship of serum levels of endogenous relaxin to cervical size in the second trimester and to cervical ripening at term. Br J Obstet Gynaecol. 1999;106:917-23.

14. lams JD, Goldsmith LT, Weiss G. The preterm prediction study: maternal serum relaxin, sonographic cervical length and spontaneous preterm birth in twins. J Soc Gynecol Invest. 2001;8:39-42.

15. Vogel I, Goepfert AR, Moller HJ, Cliver S, Thorsen P, Andrews WW. Early midtrimester serum relaxin, soluble CD163, and cervical length in women at high risk for preterm delivery. Am J Obstet Gynecol. 2006;195:208-14.

16. Davies G, Ottenhof C, Woodman M, Farley A, Julien N, Van Vugt D, Day A. Cervix length and relaxin as predictors of preterm birth. J Obstet Gynaecol Can. 2008;30:1124-31.

17. Sandager P, Uldbjerg N, Henriksen TB, Goldsmith LT, Thorsen P, Weiss G, Vogel I. Circulating relaxin and cervical length in midpregnancy are independently associated with spontaneous preterm birth. Am J Obstet Gynecol. 2009;201:31-6.

18. Kohsaka T, Min G, Lukas G, Trupin S, Campbell ET, Sherwood OD. Identification of specific relaxin-binding cells in the human female. Biol Reprod. 1998:59:991-9.

19. Hwang JJ, Macinga D, Rorke EA. Relaxin modulates human cervical stromal cell activity. J Clin Endocrinol Metab. 1996;81:3379-84.

20. Evans MI, Dougan M-B, Moawad AH, Evans WJ, Bryant-Greenwood GD, Greenwood FC. Ripening of the human cervix with porcine ovarian relaxin. Am J Obstet Gynecol. 1983;147:410-14.

21. MacLennan AH, Green RC, Bryant-Greenwood GD, Greenwood FC, Seamark RF. Ripening of the human cervix and induction of labor with purified porcine relaxin. Lancet. 1980;1:220-3.

22. MacLennan AH, Green RC, Grant P, Nicolson R. Ripening of the human cervix and induction of labor with intracervical purified porcine relaxin. Obstet Gynecol. 1986:68:595-601.

23. Bell RJ, Permezel M, MacLennan A, Hughes C, Healy D, Brennecke S. A randomized, double-blind, placebo-controlled trial of the safety of vaginal recombinant human relaxin for cervical ripening. Obstet Gynecol. 1993;82:328-33.

24. Brennand JE, Calder AA, Leitch CR, Greer IA, Chou MM, MacKenzie IZ. Recombinant human relaxin as a cervical ripening agent. Br J Obstet Gynecol. 1997;104:775-80.

25. Kelly AJ, Kavanaugh J, Thomas J. Relaxin for cervical ripening and induction of labour. Cochrane Database Syst Rev. 2001;2:CD003103.

26. Chen SA, Perlman AJ, Spanski N, Peterson SM, Sanders SW, Jaffe R, Martin M, Yalcinkaya T, Cefalo RC, Cheschier NC, Menard MK, Mordenti J. The pharmacokinetics of recombinant human relaxin in nonpregnant women after intravenous, intravaginal and intracervical administration. Pharm Res. 1993;10:834-48.

27. Bishop EH. Pelvic scoring for elective induction. Obstet Gynecol. 1964:24:266-68.

28. Golub MS, Working PK, Cragun JR, Cannon RA, Green JD. Effect of shortterm infusion of recombinant human relaxin on blood pressure in the latepregnant rhesus macaque (Macaca mulatta). Obstet Gynecol. 1994;83:85-8.
29. Golub MS, Galiher NJ, Working PK, Greenspan A. Twelve-month evaluation of rhesus monkey dams and infants after relaxin (hRlx-2) infusion in late pregnancy. Reprod Toxicol. 1996;10:29-36.

30. Ferraiolo BL, Winslow J, Laramee G, Celniker A, Johnston P. The pharmacokinetics and metabolism of human relaxins in rhesus monkeys. Pharm Res. 1991;8:1032-8.

31. Seibold JR, Clements PJ, Furst DE, Mayes MD, McCloskey DA, Moreland LW, White B, Wigley FM, Rocco S, Erikson M, Hannigan JF, Sanders ME, Amento EP. Safety and pharmacokinetics of recombinant human relaxin in systemic sclerosis. J Rheumatol. 1998;25:302-7.

32. Chyu JK, Strassner HT. Prostaglandin E2 for cervical ripening: a randomized comparison of Cervidil versus Prepidil. Am J Obstet Gynecol. 1997;177:606-11.

33. Rayburn W, Gosen R, Ramadei C, Woods R, Scott J. Outpatient cervical ripening with prostaglandin E2 gel in uncomplicated postdate pregnancies. Am J Obstet Gynecol. 1988;158:1417-23.

34. Dschietzig T, Teichman SL, Unemori E, Wood S, Richter C, Bohmer J, Richter C, Baumann G, Stangl K. Intravenous recombinant human relaxin in compensated heart failure: a safety, tolerability and pharmacodynamic trial. J Card Fail. 2009;15:182-90.

35. Teerlink JR, Metra M, Felker GM, Ponikowski P, Voors AA, Weatherley BD, Marmor A, Katz A, Grzybowski J, Unemori E, Teichman SL, Cotter G. Relaxin for the treatment of patients with acute heart failure (Pre-RELAX-AHF): a multicentre, randomized, placebo-controlled, parallel group, dose-finding phase Ilb study. Lancet. 2009:373:1429-39.

36. Teerlink JR, Cotter G, Davison BA, GFelker GM, Filippatos G, Greenberg BH, Ponikowski P, Unemori E, Voors AA, Adams Jr KF, Dorobantu M, Grinfeld R, Jondeau G, Marmor A, Masip J, Pang PS, Werdan K, Teichman SL, Trapani A, Bush CA, Saini R, Schumacher C, Severin TM, Metra M. Serelaxin, recombinant human relaxin-2, for the treatment of acute heart failure (RELAX-AHF): a randomized, placebo-controlled trial. Lancet. 2011;381:29-39.

37. Weiss G, Teichman S, Stewart D, Nader D, Wood S, Unemori E. Placebocontrolled trial of relaxin for cervical ripening in post-delivery date pregnancies. Ann NY Acad Sci. 2009;1160:385-6.

38. Quagliarello J, Lustig DS, Steinetz BG, Weiss G. Absence of a pre-labor relaxin surge in women. Biol Reprod. 1980;22:202-04.

39. Ponikowski P, Mitrovic V, Ruda M, Fernandez A, Voors AA, Vishnevsky A, Cotter G, Milo O, Laessing U, Zhang Y, Dahlke M, Zymlinski R, Metra M. A randomized, double-blind, placebo-controlled, multicentre study to assess haemodynamic effects of serelaxin in patients with acute heart failure. Eur Heart J. 2014;35:431-41.

40. Smith MC, Danielson LA, Conrad KP, Davison JM. Influence of recombinant human relaxin on renal hemodynamics in healthy volunteers. J Am Soc Nephrol. 2006;17:3192-7.

41. Halls ML, Bond CP, Sudo S, Kumagni J, Ferraro T, Layfield S, Bathgate RA Summers RJ. Multiple binding sites revealed by interaction of relaxin family peptides with mature and chimeric relaxin family receptors 1 and 2 (LGR 7 and LGR 8). J Pharmacol Exp Ther. 2005;313:677-87.

42. Bathgate RAD, Halls ML, van der Westhuizen ET, Callander GE, Kocan M, Summers RJ. Relaxin family peptides and their receptors. Physiol Rev. 2013; 93:405-80.

43. Teichman SL, Unemori E, Dschietzig T, Conrad K, Voors AA, Teerlink JR, Felker GM, Metra M, Cotter G. Relaxin, a pleiotropic vasodilator for the treatment of heart failure. Heart Fail Rev. 2009;14:321-29.

\section{Submit your next manuscript to BioMed Central and we will help you at every step:}

- We accept pre-submission inquiries

- Our selector tool helps you to find the most relevant journal

- We provide round the clock customer support

- Convenient online submission

- Thorough peer review

- Inclusion in PubMed and all major indexing services

- Maximum visibility for your research

Submit your manuscript at www.biomedcentral.com/submit 